\title{
Cinema gaúcho: um modo de fazer e ver os jovens
}

Ana Carolina D. Escosteguy', Cristiane Freitas Gutfreind ${ }^{2}$

\begin{abstract}
Resumo
Esse texto analisa o que representou a produção de Deu Pra Ti, Anos 70 (Nelson Nadotti e Giba Assis Brasil, 1981) e Houve Uma Vez Dois Verões (Jorge Furtado, 2002), num contexto regional especifico mas que articula-se ao espaço cinematográfico nacional. Ao mesmo tempo, pretende-se observar a construção discursiva dos jovens protagonistas das duas tramas citadas que, além de revelar um determinado modo de fazer cinema, denotam uma construção identitária que se articula com outros discursos em circulação na sociedade de cada periodo.
\end{abstract}

Palavras-chave: juventude, cinema, regional

\section{Abstract}

This article analyses two films, Deu Pra Ti, Anos 70 (Nelson Nadotti and Giba Assis Brasil, 1981) and Houve Uma Vez Dois Verões (Jorge Furtado, 2002), for a better understanding of what it may mean to speak of youth cinema. It intends to identify some features that connect these films to a regional cultural practice in a national social formation. Besides revealing a certain way of film making, these films also offer cinematic accounts of youth in a historically specific periods.

Keywords: youth, cinema, regional

\footnotetext{
' Doutora em Ciências da Comunicação pela Universidade de São Paulo, professora do Programa de Pós-Graduação em Comunicação Social da PUCRS e pesquisadora do CNPq. ${ }^{2}$ Doutora em Sociologia pela Université René Descartes (Paris V). $p$ rofessora do Programa de Pós-Graduação em Comunicação Social da PUCRS e editora da Revista Famecos.
} 
As atividades culturais são constitutivas de um processo social. E os produtos culturais, resultantes dessas atividades, são materializações de formações sociais. Assim, o que se pretende aqui é uma análise de formas culturais e formações sociais. Deu Pra Tti, Anos 70 (de Nelson Nadotti e Giba Assis Brasil, super-8, 110 min, 1981) e Houve Uma Vez Dois Verões (de Jorge Furtado, DV, 35mm, 75min, 2002) são tomados como textos filmicos que, além de representar a juventude em momentos históricos distintos, revelam um determinado modo de fazer cinema que diz respeito a uma formação social específica.

Neste trabalho, o cinema é entendido como uma estrutura formada por uma criação filmica que possui uma relativa autonomia, sendo essa criação organizada de acordo com o meio sociocultural ao qual ela pertence, determinando uma forma de produção específica. A organização cinematográfica tem, então, uma relação direta com o lugar onde ela é produzida, possibilitando ao cinema a capacidade de questionar sobre as relações históricas e socioculturais. Como diz JeanMichel Frodon, "existe uma solidariedade entre a história das nações e a história do cinema" (FRODON, 1998:12), as narrativas cinematográficas aparecem, assim, profundamente ligadas a maneira de viver de um local determinado, possibilitando a formação de cinematografias nacionais ou regionais, estabelecendo uma relação íntima com os meios de produção e subvenção. Por isso, a organização cinematográfica estabelece relações estreitas com a estrutura institucional estatal, acompanhando as mudanças de valores na sua formação e se diferenciando umas das outras.

E a juventude é vista como um modo de estar no mundo que obrigatoriamente leva em conta aspectos históricos e culturais das circunstâncias vividas. Sendo assim, não se trata de pensá-la como pertencendo apenas a uma faixa etária precisa o que, de certa forma, homogeneiza uma variedade de instâncias que colaboram na sua definição. Aqui, pretende-se compreendê-la como produto de relações de poder e resultado de uma série de condições sociais, portanto, uma construção cultural e relacional.

Neste sentido, não existiria uma determinação direta pela idade na consideração do ser jovem, mas diversas formas de realização conforme contextos sociais, econômicos e culturais que se vivam. Portanto, não existe uma Juventude, em maiúscula, resultado de 
uma cronologia, mas muitas "juventudes" resultado das culturas." (SERRANO, 1998:276)

São essas relações que se pretende tratar mediante a análise do que representou a produção de Deu Pra Ti, anos 70 e Houve Uma Vez Dois Verões, num contexto regional especifico mas que, por sua vez, articula-se ao espaço cinematográfico nacional. Ao mesmo tempo, pretende-se observar a construção discursiva dos jovens protagonistas das duas tramas citadas que, além de revelar um determinado modo de fazer cinema, denotam uma construção identitária que se articula com outros discursos em circulação na sociedade de cada período.

Deu Pra Ti se passa na década de 70, assinalado pela festa do tricampeonato brasileiro do Sport Club Internacional, até a virada de 1979 para 1980 e apresenta o cotidiano de um grupo de jovens universitários, centrado nos acontecimentos que envolvem Marcelo e Ceres. Destaca-se que essa década é marcada pelo Al-5, assinado em 13 de dezembro de 1968, no governo Costa e Silva, que concedeu plenos poderes ao executivo e inaugurou uma fase de fechamento até 1979 quando é revogado. Como os protagonistas da trama vivem esse periodo e uma parte da narrativa diz respeito ao seu envolvimento com o movimento estudantil, é importante, também, ressaltar que este tinha sido desmantelado em 1968 quando no 30 Congresso da UNE, em Ibiúna (SP), seus líderes foram presos. A partir de 1976 inicia lentamente sua reorganização, culminando em 1979, quando 10 mil estudantes participam do Congresso de Reconstrução da UNE. Na mesma época, no governo Geisel, o processo de abertura política é destravado, com a concessão de anistia aos condenados por crimes politicos, o relaxamento da censura e o restabelecimento do pluripartidarismo. Assim, os jovens deste filme vivem esse clima e, ainda, estão fortemente ligados a uma agenda da geração dos 60 , dividindo-se entre militância, o sonho da mudança, e prazer, diga-se festa, música - entre o rock'n' roll e a MPB e suas novas experimentações -, cinema e literatura.

Houve Uma Vez Dois Verões é o nosso passado recente. Se eles estão finalizando o $2^{\prime \prime}$ Grau no final dos 90, são crianças em 1985, ano que marca a transição do regime militar para a democracia e, ainda, em 1989 quando ocorrem as primeiras eleiçōes diretas. E permanecem na infância quando um dos últimos movimentos dos jovens no Brasil eclode e vai para as ruas reivindicar o impeachment de Fernando Collor de 
Mello que renuncia em 1992, depois do mesmo ter sido aprovado pelo Congresso. As forças que vão marcar esses jovens dizem respeito à onda ascendente do neoliberalismo e a conseqüente interpelação do indivíduo nas suas escolhas pessoais. Fica implícito nesse filme que se trata dessa geração. Ocupando essa posição é que Chico e Juca se deparam com Roza numa noite das férias de 1998. No primeiro encontro, Chico e Roza fazem sexo. Ele deixa de ser virgem, mas ela, durante a noite, desaparece. Acompanhado do amigo Juca, Chico procura a amada, numa busca sem sucesso. De volta à cidade, recebe um telefonema de Roza, que o reencontra e diz que está grávida. Depois de pagar parte da realização de um suposto aborto, ele descobre, no verão da virada para o próximo milênio, que Roza mentiu sobre a gravidez e que foi apenas mais um a sofrer o golpe.

\section{Do fazer cinema}

Levando em consideração esses dois eixos - cinema e juventude - e os dois filmes, compreende-se que existe uma produção cinematográfica que tematiza e representa a juventude, revelando que as relações entre cinema e juventude acabam, por vezes, reduzidas a uma idéia de um "cinema jovem", que é um termo extremamente vago, mas que pode ser utilizado cada vez que aparece uma nova geração de cineastas propondo uma renovação em termos técnicos, estéticos e narrativos3. Foi o que se passou no Rio Grande do Sul, mais precisamente em Porto Alegre, quando surge um grupo de jovens cineastas que se interessaram em narrar o cotidiano da juventude gaúcha dessa época.

Essa efervescência fez do estado, desde então, um pólo cinematográfico regional importante por três motivos: era sede do festival de Gramado que funcionava desde 1973 com relevante destaque no cenário nacional; possuía uma tradição em cine-clubes, o que despertava uma cultura cinematográfica formada ao longo dos anos que dialogava com o seu passado reprimido se tornando uma cultura engajada e ativa tanto para fazer quanto para fruir os filmes; e se tornou um lugar privilegiado do surto do Super 8 .

O Super 8 encontra repercussão entre os jovens realizadores brasileiros em 1972, qunado foi criado um festival do formato em São Paulo, provocando uma grande euforia, encarnando para alguns o meio 
alternativo para criar imagens, atraindo não somente jovens cineastas, mas também artistas plásticos como Hélio Oiticia, Lygia Pape e Rubens Gerscheman. Essa bitola permitiu a profissionalização de muitos jovens que sairam do amadorismo como Neville d'Almeida e Ivan Cardoso promovendo, com esse formato, uma contestação irreverente através do movimento do udigrudi.

Em 1976, o Super 8 se dissemina também em Porto Alegre através de um concurso de filmes sobre a cidade promovida pela prefeitura local, revelando toda uma geração de diretores gaúchos como Giba Assis Brasil, Carlos Gerbase e Sérgio Lerrer. Deu Pra Ti foi o marco dessa época, pois o seu sucesso permitiu a realização de uma série de outros longas-metragem filmados também em Super 8, fazendo com que esses filmes saissem de um gueto restrito à cinéfilos e fossem projetados em salas de cinema. Segundo Luiz Carlos Merten (2002:44), a produção se tornou continua, chegavam a realizar dois filmes por semana, o que fez com que os próprios diretores criassem um circuito exibidor alternativo que englobava de universidades à associação de moradores.

Com a proliferação do formato e o sucesso de Deu Pra Ti, a sua mesma equipe pôde refazer uma versão em $35 \mathrm{~mm}$ que obteve uma distribuição nacional e originou o longa-metragem Verdes Anos (1984), dessa vez Giba Assis Brasil teve Carlos Gerbase como parceiro à frente da direção. O filme baseado em um conto de Luiz Fernando Emediato traz novamente para tela a juventude gaúcha nos anos de repressão ditatorial, mesmo não sendo autobiográfico, a vivência mostrada na narrativa poderia ser indiscutivelmente a de qualquer um que compunha a equipe de produção. Assim para Merten, Verdes Anos diz respeito a "interpretação do caráter e da própria identidade do homem e da mulher nascidos no Rio Grande" (2002:63). Ao contrário de Deu Pra Ti, "os Verdes Anos" se passam no interior, mas a inquietude e a indecisão dos jovens é a mesma, não levando-se em consideração se a trama acontece longe da capital. Na verdade, o filme é uma alusão a uma produção hollywwodiana de 1960, chamada Os Anos Verdes (The Sterile Cuckoo) de Alan Pakula que mostrava as mesmas inquietações da juventude americana, inverte-se o título e os jovens continuam sem saber o que querem e a procura de emoções.

Essas produções abriram caminho para a profissionalização de outros jovens diretores gaúchos como Sérgio Amon e Werner 
Schünemann. Nesse sentido, o percurso percorrido pelas realizações em Super 8 possibilitaram a difícil façanha de profissionalizar o amadorismo e divulgar o cinema gaúcho. Além disso, as narrativas urbanas começaram a fazer parte do cenário cinematográfico do sul do país ao lado das já estabelecidas narrativas rurais, se tornando uma influência marcante para as gerações seguintes de realizadores.

Por outro lado, Houve Uma Vez Dois Verões foi realizado no final do período do cinema brasileiro conhecido como Retomada. Sabemos que depois da crise que atingiu o cinema nacional entre 1990 e 1994, os filmes voltaram a ser produzidos devido aos incentivos fiscais, mas também a uma cultura cinematográfica enraizada no imaginário das pessoas formada ao longo do tempo devido a uma filmografia reconhecida e consolidada no curta-metragem e a abertura de um diálogo com gêneros e movimentos do passado. Esse diálogo com as suas origens permitiu ao cinema brasileiro se renovar, criar imagens plurais suscetíveis de dar conta das imagens locais, diferenciando-as por vezes de uma certa padronização e colocando-a em sintonia com o público.

Assim, como na política, os tempos de ruptura e efervescência tinham se aquietado, estávamos em uma fase no cinema brasileiro em que se valorizava o pragmatismo, ou seja, o importante era fazer filmes com os meios, em termos de produção e de técnica, que estivessem disponíveis. Não tinha mais espaço para movimentos, como o do Super 8 , nem para grandes rupturas estéticas, pois o tempo privilegiava as pequenas histórias, o cotidiano, e não mais, a contestação de valores, mas a aceitação do mundo da maneira como ele nos é apresentado.

Ao contrário dos jovens cineastas iniciados pelo Super 8 para a realização de longa-metragem, Jorge Furtado já era um autor reconhecido em todo país, desde o premiado sucesso (nacional e internacional) do curta-metragem Ilha das Flores (1989)4, além das suas incursões como roteirista e diretor de televisão, gerando, assim, uma grande expectativa, sobretudo da crítica, em relação ao seu primeiro longa-metragem para o cinema. $O$ diretor opta por uma realização "alternativa" tanto, no que diz respeito a temática quanto a forma de produção. Furtado busca inspiração na televisão para fazer um filme sobre e para jovens, realizado em vídeo e kinescopado, além de se constituir em uma produção de baixo orçamento.

Podemos afirmar, então, que a proposta de Furtado nos remete a questões de ordem técnica (diz respeito ao formato) ou de inovações 
da ordem da representação (diz respeito à estética), ou seja, partindo da idéia de que as tecnologias são um meio, elas têm por objetivo reativar antigas questões, principalmente, sobre a idéia de representação. Assim, podemos entender a obra de Furtado como uma transição entre a linguagem do cinema e da televisão, tendo como objetivo propor transformações na idéia de representação cinematográfica, através da migração da linguagem televisiva para o cinema e vice-versa e do uso da agilidade da forma publicitária.

Tal fato nos remete a construção e importância da sintonia entre a televisão e o público no Brasil, ao desejo do cineasta de encontrar esse público, atrelando a criatividade da linguagem televisiva a uma história típica dos jovens classe média, embalada por sol, namoros e (des)encontros afetivos.

\section{Do modo de ver os jovens}

Estabelecidas as relações entre um determinado modo de fazer cinema, num contexto específico e por uma determinada geração, procura-se identificar as particularidades dos jovens nos próprios filmes.

Trata-se de assumi-los como agentes sociais específicos, conservando, portanto, um distanciamento de entendimentos que associam o jovem a um grupo homogêneo, inter ou transclassista devido especialmente ao compartilhamento de uma idade, de gostos e preferências, revelados pelo consumo de certos bens e produtos culturais. Na tentativa de evitar tal associação, identificamos que essas narrativas filmicas tratam de uma determinada juventude, isto é, dos jovens da classe média e suas angústias, em distintos momentos históricos - virada dos anos 70 para os 80 e passagem do século XX para o XXI.

Em Deu Pra Ti, Anos 70, os protagonistas da narrativa são todos jovens universitários que moram com suas famílias e aparentemente não têm problemas financeiros. Sua atividade principal é, sobretudo, estudar, embora alguns possam realizar alguma tarefa remunerada. Além do engajamento de alguns no movimento estudantil, perambulam pelos bares, vão ao Alaska, ícone do movimento estudantil da época, e ao Ribs, um dos primeiros lugares de fast-food de Porto Alegre, localizado em bairro nobre e da elite porto-alegrense. Junto com isso, a tríade sexo, drogas - até aquela data, ainda, restrita a maconha - e rock'n'roll fazem a cabeça da gurizada. 
Mais moços que esses, os jovens de Houve Uma Vez estão terminando o $2^{\circ} \mathrm{Grau}$ e planejam entrar na universidade. Sem problemas financeiros, embora os pais escolham para tirar férias o mês de março "porque é mais barato" na "maior e pior praia do mundo". Contudo, ao longo do filme, a situação financeira da família de Chico, um dos protagonistas da trama, melhora, pois no ano seguinte as férias já são em dezembro e o plano é que no futuro possam ir à praia em janeiro. Juca, seu amigo, também de férias no mesmo período, demonstra ter o suficiente para sentar num bar/restaurante, comer pizza, beber um vinho e, ainda, oferecer ao amigo Chico cem reais se ele conseguir uma amiga para saírem juntos. No retorno à cidade, Chico, em sua casa, tem computador e telefone no quarto, toca teclado, além de estar preocupado na escolha de uma camiseta para vestir no reencontro com Roza. Portanto, há muitos indícios de que os dois guris, também, são da classe média.

Dentre as distintas possibilidades postas pelos filmes em análise para tratar das preocupações de tal juventude, destacamos a relação com os pais e com a cultura vigente do período, a preocupação com o futuro, incluídos nesse âmbito a escolha da carreira profissional, ir morar fora da casa dos pais, e, finalmente, as conquistas amorosas e experiências sexuais. $O$ engajamento político dos jovens não assumirá um papel central nesta análise, dado sua evidente inexistência no cotidiano da juventude da virada do século XX para o XXI, posta em cena em Houve Uma Vez Dois Verões.

Sobre as relações entre uma determinada cultura jovem e sua associação com expressões culturais do período e, também, com a cultura dos pais, em Deu Pra Ti, Anos 70, Marcelo, protagonista da trama, mora com seus pais, tem seu próprio quarto, decorado com um pôster de Jimi Hendrix, ouve som com seus fones e escreve poesia. O fato de escrever poesia indica que se trata, ainda, de uma geração que dá atenção e importância para a literatura o que mais tarde vai se perder. Herança da geração de 68 persistia, também, uma afinidade da turma retratada no filme com a música e o cinema. Assim, as festas embaladas por Rolling Stones e outros, bem como as idas ao cinema são motivos de congraçamento da turma. Dado que o contexto histórico de Houve Uma $\mathrm{Vez}$ Dois Verões é outro, destaca-se que neste os jovens relacionam-se com a cultura eletrônica, fliperama e games no computador. Não há nenhuma referência à literatura, ao cinema e mesmo à música. 
Em relação aos pais, observa-se em diversas situações a ausência de diálogo entre pais e filhos, especialmente, em Deu Pra Ti, Anos 70. Por exemplo, Marcelo, embora tenha decidido abandonar Porto Alegre e compartilhe essa idéia com Ceres, revela que seus pais não sabem de sua decisão. Algo semelhante ocorre com a própria Ceres que vai para a praia num final de semana de carona e com o namorado, mas diz para a mãe que é com a turma e de ônibus. Esta, por sua vez, resume o que vai acontecer: o pai de Ceres não vai gostar daquele programa. A geração mais velha neste filme aparece especialmente através da presença da mãe, o pai é apenas mencionado como referência importante na familia, mas está ausente da trama. En Houve Uma Vez Dois Verões, as relações familiares são inexistentes, embora o pai seja o motivo pelo qual a família vai para a praia em março. Também, é decorrente da melhoria da posição do pai as férias em dezembro no ano seguinte, assim como o planejamento das próximas para janeiro. De resto, a família não aparece.

Em Deu Pra Ti, Anos 70 a preocupação com o futuro se relaciona com o que se vai fazer profissionalmente. Ceres questiona sua opçào pela arquitetura, assim como Marcelo a pelo jornalismo. Já em Houve Uma Vez Dois Verões, os dois protagonistas não tematizam essa questão, apenas marginalmente tal tema aparece na conversa inicial entre Chico e Roza. De um lado, porque estão em férias, mas as conversas revelam uma preocupação central com "matar o tempo" e efetivar a primeira transa. Em relação a esse último tema, em Deu Pra Ti, Anos 70, vivese um tempo de descoberta das relações sexuais onde estas são tratadas sem problematização, embora os jovens assumam suas "transas" abertamente.

Apesar de serem jovens da classe média os que estão representados nesses dois filmes, as circunstâncias históricas distinguem esses jovens. A dolorosa tormenta dos anos 70 , em que a luta armada e a repressão deram início a um lento processo de recuperação dos direitos civis, é abordada sob uma perspectiva diferente nesses filmes gaúchos. A visão retrospectiva dessa época está inscrita no afrontamento da dramaturgia através de um olhar interrogativo do jovem. As reconstituições naturalistas acabam sendo abandonadas, assim como um engajamento político, em proveito dos personagens, delimitados pela sua ambigüidade entre o compromisso político e a procura de um encontro afetivo. 
No restante do país, ao contrário, os filmes que tinham a juventude como tema, priorizavam o culto ao corpo, ao sol e ao surf como em Nos Embalos de Ipanema (1978), Menino do Rio (1981) e Garota Dourada (1984), todos dirigidos por Antonio Calmon ou em filmes que retratavam uma certa ambigüidade, associando jovens, drogas e delinqüência, como em Amor Bandido (Bruno Barreto, 1978).

Podemos afirmar, então, que no sul do país, o vazio provocado na juventude pela sufocação das utopias e pela repressão, regida pelo autoritarismo, está inscrita no centro de filmes em que a descontração se deixa, por vezes, marcar pela angústia como Deu Pra Ti, Vedes Anos, Me Beija (Werner Schünemann, 1984) e Aqueles dois (Sérgio Amon, 1985), feitos por grupo de jovens realizadores que se interessavam ao mesmo tempo por literatura, teatro e cinema. Isso demonstra a especificidade dos filmes gaúchos.

Já se compararmos Houve Uma Vez Dois Verões com o resto do país, percebemos que é um filme singular em relação aos outros realizados no mesmo período, pois apresenta a juventude de forma diferenciada buscando descobertas individuais, em um cenário de férias e praia, longe da violência. Nos filmes brasileiros dessa época o jovem aparece desesperançado com necessidade de escapar de um universo sem grandes perspectivas como, por exemplo, em Terra Estrangeira (Walter Salles e Daniela Thomas, 1996) e A Ostra e o Vento (Walter Lima Júnior, 1997), ou ainda aparece atrelado à violência urbana, marcada por um espaço demarcado (sobretudo pelas favelas e/ou periferias), com um estilo de vida próprio de zonas de fronteiras, ou seja, lugares com regras específicas de poder que tornam a interação social estranha a qualquer noção de humanidade e onde as instituições são ausentes. Essa temática é vista em filmes Como Nascem Os Anjos (Murilo Salles, 1996), passando por Uma Onda No Ar (Helvécio Ratton, 2002) para chegar a um filme que levou ao extremo a violência urbana, Cidade de Deus (Fernando Meirelles e Kátia Lund, 2002).

A partir daí podemos afirmar que Houve Uma Vez, se diferencia tanto do movimento do Super 8 dos anos 70, quanto dos filmes contemporâneos que tem o jovem como temática, se distanciando de uma proposta política e de espaços periféricos, se voltando para a classe média e os seus problemas afetivos, reforçando uma linguagem estética próxima da televisão. 


\section{De uma análise ainda incipiente}

O espaço das relações entre cinema e juventude ainda está para ser explorado, em especial nas suas conexões mais especificas entre a produção nacional e a regional, dado que o que ora se apresenta é apenas uma visão inicial. Podemos afirmar que assim como a idéia de uma identidade nacional é rarefeita, a de uma cinematografia brasileira também o é.

No que diz respeito ao cinema gaúcho, este valoriza o seu espaço cinematográfico elegendo a região como cenário para criar e fruir narrativas sustentadas por uma estética marcada pelos aspectos socioculturais do lugar, mas através de histórias universais que se regionalizam pelo jeito de fazer e ver, idéia reforçada pelo movimento do Super 8 porto alegrense e de certa forma pela experiência de produção de Houve Uma Vez Dois Verões.

Portanto, há uma criação estética especifica da região, oriunda do movimento iniciado no final dos anos $70 \mathrm{com}$ o Super 8, enfatizando a temática juvenil e urbana que se alastrou em seguida pelo resto do país, embora revelando traços característicos. Tal fato tem continuidade até hoje, contando entre seus expoentes na criação filmica gaúcha com Giba Assis Brasil e Carlos Gerbase.

Na trilha de Deu Pra Ti, passando por Ilha das Flores e chegando a Houve Uma Vez, o Rio Grande do Sul se consolida como um importante pólo cinematográfico no país, inovador em termos de formatos e uso de diferentes linguagens, com uma cultura cinematográfica enraizada que prestigia os longas-metragem locais. No entanto, vale destacar a vasta produção de curtas-metragem, subvencionados pelas trocas entre televisão e cinema e exibidos por emissoras locais5, além de uma proliferação de escolas de cinema em nivel universitário formando profissionais para um mercado cada vez mais em expansão.

No que diz respeito ao modo de ver os jovens na passagem de Deu Pra Ti para Houve Uma Vez, o sonhou acabou. Isso, sobretudo, torna-se emblemático para a juventude brasileira que viveu a década de 70. A garra, a paixão e o radicalismo da geração 68 foram abruptamente interditados. Restou a clandestinidade e um lento retorno ao primeiro plano da cena através da reorganização do movimento estudantil onde ainda reverberava uma possibilidade de mudança. Com o passar do 
tempo, as utopias revolucionárias faliram, veio a frustração dos 80 e o desencadeamento de compromissos cada vez mais itinerantes, portanto, a ausência de projetos de longo prazo e uma atuação marcada pelo tempo presente e com compromissos consigo próprio. Mas se a canção de 70 de Lennon chancelava o fim de uma época, também, vislumbrava o futuro: "Eu não acredito em Kennedy/Eu não acredito em Buda/Eu não acredito em mantra/Eu não acredito em $\mathrm{Gita} / \mathrm{Eu}$ não acredito em yoga/Eu não acredito em reis/Eu não acredito em Elvis/Eu não acredito em Zimmerman/Eu não acredito em Beatles/Eu só acredito em mim".

Em sendo assim, a angústia embasada por um período de efervescência político-social do jovem em Deu Para Ti deu lugar a uma angústia centrada no indivíduo e no conformismo do jovem em Houve Uma Vez, mas cada um dos filmes ressaltando ao seu modo a especificidade de um cinema feito no extremo sul do país.

\section{Referências bibliográficas}

ABRAMO, Helena Wendel et al. (org.). Retratos da juventude 104 brasileira: análises de uma pesquisa nacional. São Paulo: Fundação Perseu Abramo, 2005.

BECKER, Tuio. Caderno Porto\&Vírgula $n^{\circ}$ 8: Cinema no Rio Grande do Sul. Porto Alegre: Unidade Editorial Porto Alegre, 1995.

BRANDÃO, Antônio Carlos. Movimentos culturais de juventude. São Paulo: Moderna, 1993.

ESCOSTEGUY, Ana Carolina D. e GUTFREIND, Cristiane Freitas. Identidade gaúcha e cinematografia regional na mídia impressa local. Revista Logos, n²4, p. 28-37, 2006.

FRODON, Jean-Michel. La projection nationale. Paris: Odile Jacob, 1998.

GUTFREIND, Cristiane Freitas. Un cinéma possible: une analyse socio-anthropologique de la production cinématographique brésilienne des annés 90 . Tese de Doutoramento apresentada na Université René Descartes - Pariș V(Sorbonne), 2001. 
MERTEN, Luiz Carlos. A aventura do cinema gaicho. São Leopoldo: Editora Unisinos, 2002.

OLIVEN, Ruben. A parte o todo - A diversidade cultural no Brasil-nação. Petrópolis: Vozes, 2006. (2 edição revista e ampliada)

ORICCHIO, Luiz Zanin. Cinema de novo : um balanço critico da retomada. São Paulo: Estação Liberdade, 2003.

PARANAGUÁ, Paulo Antônio (org.). Le Cinéma Brésilien. Paris: Centre Georges Pompidou, 1987.

SERRANO, JOSÉ FERNANDO. La investigación sobre jóvenes: estudios de (y desde) las culturas. In: MARTÍN-BARBERO, Jesús e ROCHE, Fabio López de la (orgs.). Cultura, medios y sociedad. Bogotá: Universidad Nacional de Colombia Bogotá, 1998.

WILLIAMS, Raymond. Sociología de la cultura. Barcelona: Paidós, 1994.

\section{Notas}

3 Esse termo também é uma clara alusão aos movimentos cinematográficos como o britânico Free Cinema e o francês Nouvelle Vague que marcaram a história do cinema e permitiram um desencadeamento de outros movimentos realizados por jovens em diferentes partes do mundo.

4 Itha das Flores narra a trajetória de um tomate do plantio ao lixo, usando uma linguagem criativa, irreverente e irônica, mostra o desalento através do riso.

5 Desde 2000, a RBS TV veicula o programa Curtas Gaúchos, que exibe curtas-metragem realizados no Rio Grande do Sul, além de outros projetos que dão espaço para produções de cineastas do estado. 
106 